Article

\title{
Sustainable Method for the Synthesis of Alternative Bis(2-Ethylhexyl) Terephthalate Plasticizer in the Presence of Protic Ionic Liquids
}

\author{
Aleksander Grymel ${ }^{1}$, Piotr Latos ${ }^{2} \mathbb{D}$, Karolina Matuszek ${ }^{3} \mathbb{D}$, Karol Erfurt ${ }^{2} \mathbb{D}$, \\ Natalia Barteczko ${ }^{2}$, Ewa Pankalla ${ }^{1}$ and Anna Chrobok ${ }^{2, *}$ \\ 1 Grupa Azoty Zakłady Azotowe Kędzierzyn, S.A., Mostowa 30A, 47-220 Kędzierzyn-Koźle, Poland; \\ Aleksander.Grymel@grupaazoty.pl (A.G.); Ewa.Pankalla@grupaazoty.pl (E.P.) \\ 2 Department of Chemical Organic Technology and Petrochemistry, Silesian University of Technology, \\ Krzywoustego 4, 44-100 Gliwice, Poland; Piotr.Latos@polsl.pl (P.L.); Karol.Erfurt@polsl.pl (K.E.); \\ Natalia.Barteczko@polsl.pl (N.B.) \\ 3 School of Chemistry, Monash University, Clayton, VIC 3800, Australia; Karolina.Matuszek@monash.edu \\ * Correspondence: Anna.Chrobok@polsl.pl; Tel.: +48-32-237-20-14
}

Received: 2 April 2020; Accepted: 21 April 2020; Published: 23 April 2020

\begin{abstract}
Inexpensive Brønsted acidic ionic liquids based on trimethylamine and sulfuric acid are proposed as both solvents and catalysts in the synthesis of alternative plasticizer bis(2-ethylhexyl) terephthalate, which has a broad spectrum of applications in plasticization processes. The utilization of $50 \mathrm{~mol} \%$ of Brønsted ionic liquid led to the full conversion of terephthalic acid after $8 \mathrm{~h}$ of reaction at $120{ }^{\circ} \mathrm{C}$. Additionally, a $100 \%$ selectivity of bis(2-ethylhexyl) terephthalate was obtained. The advantage of the presented reaction system is based on the formation of a biphasic system during the reaction. The bottom phase consists of an ionic liquid and water, and the upper phase is created by the ester and unreacted alcohol. This phenomenon helps overcome the equilibrium of the reaction and drives it towards a high yield of product. The presented new approach is proposed as a safe, cost-effective, and alternative method to conventional processes with organometallic compounds that, in turn, leads to greener and a more economically viable technology.
\end{abstract}

Keywords: plasticizers; acidic catalysis; terephthalate esters; ortho-phthalate esters; esterification; solvents; ionic liquids

\section{Introduction}

In the recent years, strict regulations on environmental protection has intensified pending restrictions on plasticizers production, limiting the use of some ortho-phthalates esters, due to the concerns about negative effects on human health [1]. Plasticizers are important additives to improve the flexibility, plasticity, and processability of polymers [2]. These additives, which make polyvinylchloride (PVC) flexible, are massively used for the production of medical tubing and bags, toys for children, wires and cables, and many others. Non-phthalate alternative plasticizers include terephthalates, citrates, phosphates, polyesters, halogenated alkanes, and epoxy compounds [3]. Terephthalate esters have been proven to have different toxicological profiles [4] compared to ortho-phthalates, and they may be used as direct replacements, thus creating an emerging alternative market. Today, the most commercially used terephthalate ester is bis(2-ethylhexyl) terephthalate, which is used as a plasticizer in materials applied as containers for food and drinking water.

The main group of catalysts for the production of terephthalates esters are compounds that are soluble in a reaction mixture containing a sulfone group $\left(-\mathrm{SO}_{3} \mathrm{H}\right)$. In this group, methanesulfonic and para-toluenesulfonic acids, as well as ion exchange resins in hydrogen form, are crucial $[5,6]$. 
However, organometallic compounds are currently the most dominant catalysts used at the industrial scale [7-12]. Among them, titanium, zirconium, tin, antimony, and zinc compounds have been claimed in patents [5-12]. Most of the patents belong to Mitsubishi Chemical and Eastman Chemical representing the Asian and American markets, who are the largest consumers of soft PVC products. The subjects of the patent claims are process conditions, the compositions of catalysts, or specific design of the reactor. The advantage of titanium compounds is their commercial availability in large quantities and low price. Titanium compounds are catalysts for not only esterification reactions but also isomerization, transesterification, and disproportionation reactions. The selectivity of the catalyst is crucial for pure and efficient synthesis of terephthalates esters. Water formed during the process is removed from the reaction mixture in the form of an azeotrope distillation with alcohol, which is separated after being condensed and recycled in part or in whole to the reaction. Elevated temperatures can increase the reaction rate, but, simultaneously, side reactions can occur, and these cause the formation of colored by-products. Reaction temperatures using titanium- or zirconium-based catalysts are in the range of $160-270{ }^{\circ} \mathrm{C}$. The reaction temperature can be controlled by increasing or decreasing the pressure in the reaction system, which is preferable for low-boiling alcohols.

It should be noted that some companies receive bis(2-ethylhexyl) terephthalate via two methods [13]. The first method is based on the esterification of terephthalic acid with an excess of octanol, while the second one assumes the transesterification of dimethyl terephthalate (DMT) with octanol to dioctyl terephthalate, both in the presence of organometallic compounds as catalysts. In the transesterification reaction, methanol is a byproduct instead of water. The disadvantages of the transesterification reaction are a higher temperature compared to the esterification reaction and a significant dilution of the reaction mixture with octanol. Additionally, dimethyl terephthalate is more expensive than terephthalic acid, and this can influence the cost of the esterification process.

The low solubility of terephthalic acid in common solvents makes its industrial production very difficult and not environmentally benign. In our previous work, the solubility of terephthalic acid in ionic liquids was studied, and the results showed that terephthalic acid is partially soluble in ionic liquids, such as 1-ethyl-3-methylimidazolium diethylphosphate, 1-butyl-3-methylimidazolium acetate, and dialkylimidazolium chlorides up to four times higher than in DMSO (20 g of terephtalic acid per $100 \mathrm{~g}$ DMSO at $25^{\circ} \mathrm{C}$ ) [14]. Even though the solubility of terephthalic acid increased in the ionic liquid, the problem was not entirely solved. The potential application of ionic liquids for esterification process can still cause acid crystallization and clogging in the production plant.

The state-of-the-art process assumes the use of ionic liquids for the synthesis of terephthalates as solvents together with the addition of acidic catalysts (sulfuric, phosphoric, methanesulfonic acid, ion exchange resins, and zeolites) or organometallic compounds [15-18]. The reaction can be carried out using a classical method with the azeotropic distillation of water in the presence of an excess of alcohol to shift the equilibrium towards the product formation. The most often used ionic liquids are quaternary ammonium or imidazolium salts, where the production via quaternization reaction is expensive, environmentally burdensome, and, therefore, economically unfavorable.

Using a new family of Brønsted acidic protic ionic liquids, based on sulfuric acid for esterification processes of acetic [19] and lactic acid [20], we have already achieved competitive advantages over the classical methods. Highly acidic protic ionic liquids were obtained in the simple reaction between amine (e.g., triethylamine or 1-methylimidazole) and sulfuric acid. Using an excess of sulfuric acid to amine (molar ratio of 1:2-1:3; mole fraction $\chi_{\mathrm{H}_{2} \mathrm{SO}_{4}}=0.67$ and 0.75 ) led to the formation of a hydrogen-bonded network of sulfuric acid molecules and hydrogen sulfate anions in an anion structure $\left[\left(\mathrm{HSO}_{4}\right)\left(\mathrm{H}_{2} \mathrm{SO}_{4}\right)_{\mathrm{x}}\right]^{-}(\mathrm{x}=1$ or 2$)$ with a protonated base:

$$
\begin{array}{cr}
\mathrm{H}_{2} \mathrm{SO}_{4}+\mathrm{Et}_{3} \mathrm{~N} \rightarrow\left[\mathrm{Et}_{3} \mathrm{NH}\right]\left[\mathrm{HSO}_{4}\right] & \left(\chi_{\mathrm{H}_{2} \mathrm{SO}_{4}}=0.50\right) \\
\mathrm{H}_{2} \mathrm{SO}_{4}+\mathrm{Et}_{3} \mathrm{~N} \rightarrow\left[\mathrm{Et}_{3} \mathrm{NH}\right]\left[\mathrm{HSO}_{4}\left(\mathrm{H}_{2} \mathrm{SO}_{4}\right)\right] & \left(\chi_{\mathrm{H}_{2} \mathrm{SO}_{4}}=0.67\right) \\
\mathrm{H}_{2} \mathrm{SO}_{4}+\mathrm{Et}_{3} \mathrm{~N} \rightarrow\left[\mathrm{Et}_{3} \mathrm{NH}\right]\left[\mathrm{HSO}_{4}\left(\mathrm{H}_{2} \mathrm{SO}_{4}\right)_{2}\right] & \left(\chi_{\mathrm{H}_{2} \mathrm{SO}_{4}}=0.75\right)
\end{array}
$$


Ionic liquids synthesized from equimolar amounts of amine and sulfuric acid, based on $\left[\mathrm{HSO}_{4}\right]^{-}$ anions are poorly active in the esterification process [21]. When protic ionic liquids $\left(\chi_{\mathrm{H}_{2} \mathrm{SO}_{4}}=0.67\right.$ and 0.75) are used for the esterification reaction, the formation of biphasic systems was the driving force of this process and caused a shift in the equilibrium to the product formation. The insolubility of ester was a key parameter for the success of this method.

Herein, we propose inexpensive Brønsted acidic ionic liquids as solvents and catalysts for the sustainable synthesis of bis(2-ethylhexyl) terephthalate from terephthalic acid and 2-etyl-1-hexanol. This new approach is safe, cost-effective, and can be attractive as a replacement of conventional acids and organometallic compounds for industrially relevant processes.

\section{Results and Discussion}

In order to lower the cost of ionic liquids, inexpensive feedstocks such as sulfuric acid and simple amines were combined into a protic ionic liquids containing hydrogen sulfate anions [19]. Proper amine selection is crucial, as the production cost of ionic liquids mainly depends on its price [22].

As presented on Figure 1, the acidity of protic ionic liquids based on sulfuric acid, expressed by Gutmann acceptor number (AN) [23], does not depend on the $\mathrm{pK}_{\mathrm{a}}$ of amine (triethylamine, 1-methylimodazol, 2-methylpyridine, and 1-methylpyrrolidine) [19]. Therefore, for this study, we chose trimethylamine, which is the cheapest raw material.
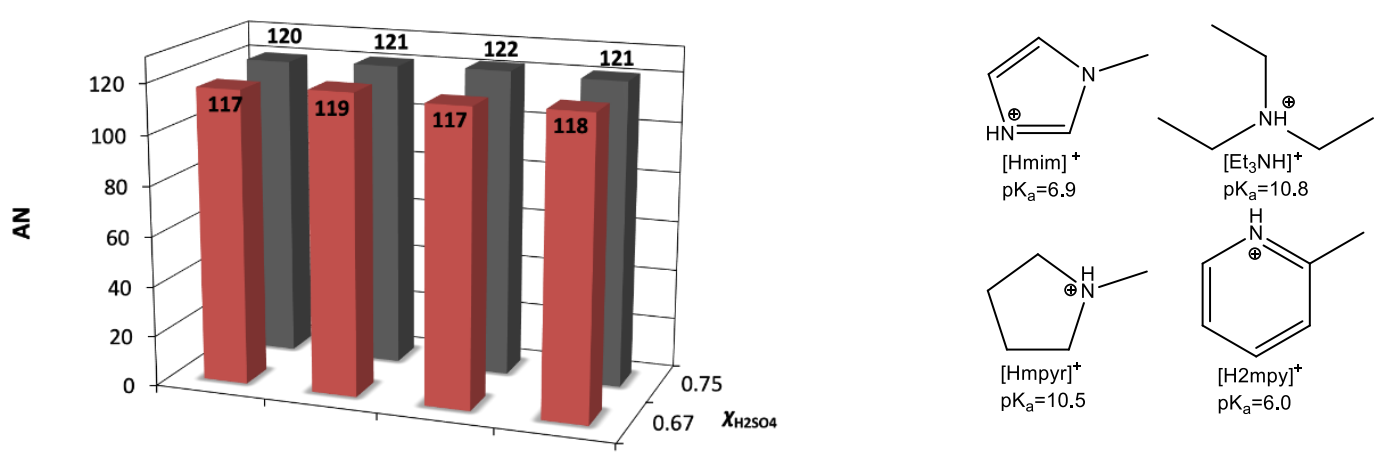

Figure 1. Gutmann acceptor number (AN) values measured for protic ionic liquids (left), based on four different amines (right) and excess of $\mathrm{H}_{2} \mathrm{SO}_{4}$ (mole fraction $\chi_{\mathrm{H}_{2} \mathrm{SO}_{4}}$ ) [19].

Ionic liquids based on the trimethylammonium cation $\left[\mathrm{Et}_{3} \mathrm{HN}\right]^{+}$and, for comparison, the more expensive 1-methylimidazolium cation $[\mathrm{Hmim}]^{+}$, were synthesized by mixing the amine with an excess of sulfuric acid (molar ratios of 1:1.5; 1:2, 1:2.7, and 1:3). All ionic liquids were slightly yellow liquids at room temperature and characterized by NMR analysis (NMR spectra available in supplementary materials).

The key to a successful esterification, utilizing protic ionic liquids, is based on the formation of a biphasic system during the reaction. The bottom phase should consist of an ionic liquid and water, and the upper phase should be created by the ester and unreacted alcohol. We assumed, based on previous studies [14-18], that this system would overcome the equilibrium and obtain a product with a high yield.

Unfortunately, the solubility of terephthalic acid in the protic ionic liquids based on sulfuric acid is very low. To resolve this, in the beginning of the process, terephthalic acid was suspended in the ionic liquid. In the next step, 2-ethyl-1-hexanol was added (Scheme 1). The reaction was carried out in a $250 \mathrm{~mL}$ rector with a thermostatic cooling/heating jacket, a mechanical stirrer, and a condenser. The samples were taken from the reaction mixture and were analyzed using gas chromatography (GC). We started the optimization of process parameters by setting out the excess of alcohol per terephthalic acid (molar ratio of 8:1). The reaction was carried at $120^{\circ} \mathrm{C}$. In preliminary experiments, the influence of the structure of the amine and the composition of ionic liquids were studied. As presented in Figure 2, 
ionic liquids based on $\left[\mathrm{Et}_{3} \mathrm{HN}\right]^{+}$and $[\mathrm{Hmim}]^{+}$cations (the molar ratios of amine to sulfuric acid being $1: 3$ and 1:2.7) were equally active in the esterification process, yielding quantities of ester after $4 \mathrm{~h}$ of reaction. However, when lowering the acidity of the ionic liquid by reducing the contribution of sulfuric acid in the ionic liquid structure (with molar excesses of $1: 2$ and 1:1.5, respectively, for $\left[\mathrm{Et}_{3} \mathrm{HN}\right]^{+}$ and $[\mathrm{Hmim}]^{+}$cations), a decrease in the activity of catalyst was observed. In both cases, after a longer reaction time, the whole conversion of terephthalic acid was achieved (after 5 and $14 \mathrm{~h}$, respectively, for the $\left[\mathrm{Et}_{3} \mathrm{HN}\right]^{+}$and $[\mathrm{Hmim}]^{+}$cations).

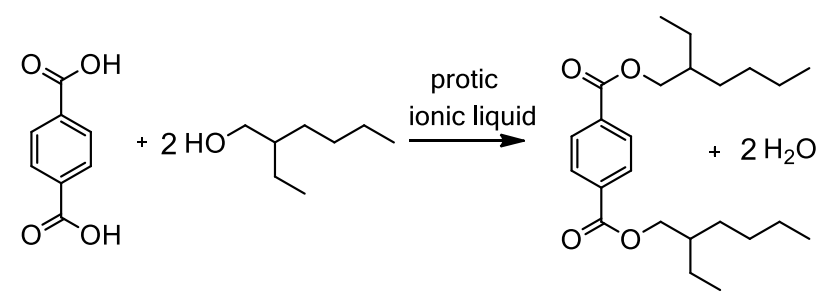

Scheme 1. Esterification of terephthalic acid with 2-ethyl-1-hexanol.

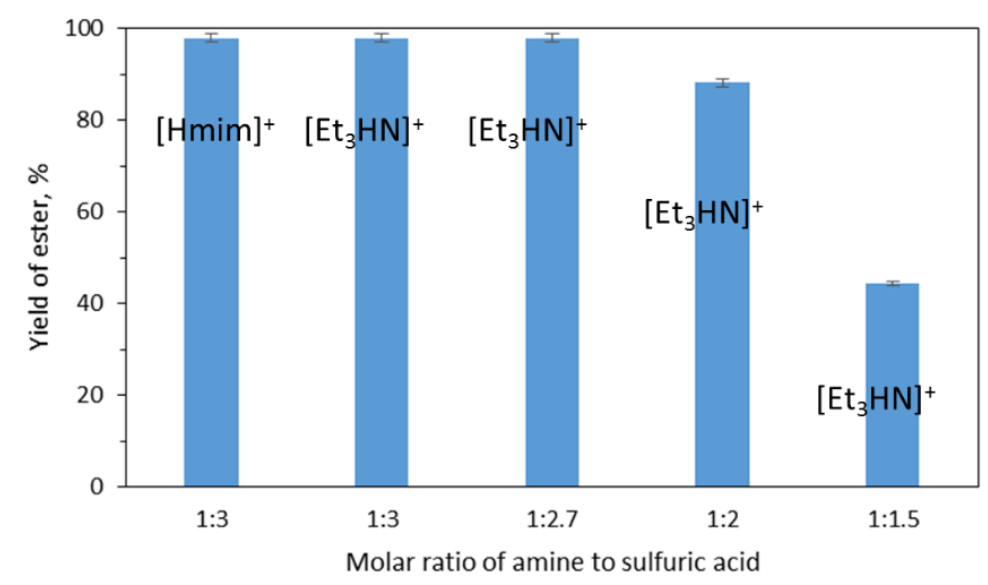

Figure 2. The influence of ionic liquids composition on the yield of bis(2-ethylhexyl) terephthalate obtained in the reaction of terephthalic acid $(0.12 \mathrm{~mol})$ with 2-ethyl-1-hexanol $(0.96 \mathrm{~mol})$ in the presence of $50 \mathrm{~mol} \%$ of the protic ionic liquid relative to terephthalic acid at $120^{\circ} \mathrm{C}$ after $4 \mathrm{~h}$.

The application of the composition of the ionic liquid below molar ratio of 1:3 was more favorable for two reasons. First, the color of the post reaction mixtures (upper phase) was almost colorless (Scheme 2), and using the ionic liquid below the ratio of 1:3 neared and then achieved a completely colorless mixture from the 1:2 ratio.

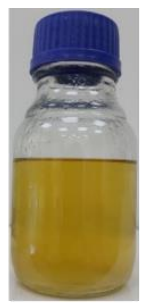

$1: 3$

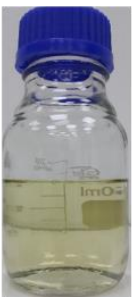

$1: 2.7$

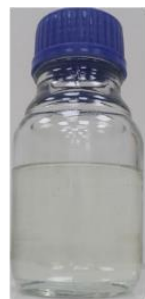

$1: 2$

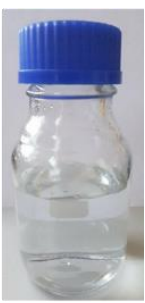

1:1.5

Scheme 2. The color of the upper phase of post reaction mixture obtained in the reaction of terephthalic acid $(0.12 \mathrm{~mol})$ with 2-ethyl-1-hexanol $(0.96 \mathrm{~mol})$ in the presence of $50 \mathrm{~mol} \%$ of the ionic liquid based on $\mathrm{Et}_{3} \mathrm{~N}$ relative to terephthalic acid at $120^{\circ} \mathrm{C}$ after $4 \mathrm{~h}$.

The second reason was the low content of the bis(2-ethylhexyl) ether created as a by-product. The high temperature and the acidity of the ionic liquid were also favorable factors for the etherification 
of alcohol. Tables 1 and 2 summarize the data on the influence of temperature and ionic liquid composition on the formation of the ether. The composition of the ionic liquid (1:2.7) could be the best solution to overcome these issues. At $120^{\circ} \mathrm{C}$, the reaction time required to obtain the product with a high yield (ionic liquid (1:2.7); yield 99.1\%) was the same as for the ionic liquid (1:3), but the level of ether was much lower than for the higher composition (1:3). In the case of ionic liquids (1:3), higher selectivity could be obtained by decreasing the temperature to $110^{\circ} \mathrm{C}$. However, the yield of the ether was still higher than for the reaction with the ionic liquid $(1: 2.7)$ at $120^{\circ} \mathrm{C}$. Additionally, the color of the post reaction mixture (1:2.7) was acceptable. Therefore, an ionic liquid based on $\mathrm{Et}_{3} \mathrm{~N}$ (composition 1:2.7) at a temperature of $120^{\circ} \mathrm{C}$ was chosen for the next few experiments.

Table 1. Influence of ionic liquid composition on the formation of bis(2-ethylhexyl) ether during the reaction at $120^{\circ} \mathrm{C}$.

\begin{tabular}{ccccc}
\hline Molar Ratio $\mathrm{Et}_{\mathbf{3}} \mathbf{N}: \mathbf{H}_{\mathbf{2}} \mathbf{S O}_{\mathbf{4}}$ & $\mathbf{1 : 3}$ & $\mathbf{1 : 2 . 7}$ & $\mathbf{1 : 2}$ & $\mathbf{1 : 1 . 5}$ \\
\hline Yield of ester, \% & 99.5 & 99.1 & 99.2 & 99.7 \\
(time, h) & $(4)$ & $(4)$ & $(5)$ & $(14)$ \\
Yield of ether, \% & 23.1 & 2.5 & 2.2 & 1.7 \\
(time, $\mathrm{h}$ ) & $(4)$ & $(4)$ & $(4)$ & $(4)$ \\
\hline
\end{tabular}

Table 2. Influence of temperature on the formation of bis(2-ethylhexyl) ether after $4 \mathrm{~h}$.

\begin{tabular}{ccc}
\hline Temp., ${ }^{\circ} \mathbf{C}$ & $\begin{array}{c}\text { Yield of Bis(2-Ethylhexyl) Ether, } \% \\
\text { Ionic Liquid 1:3 }\end{array}$ & $\begin{array}{c}\text { Yield of Bis(2-Ethylhexyl) Ether, \% } \\
\text { Ionic Liquid 1:2.7 }\end{array}$ \\
\hline 90 & 0.7 & 0.6 \\
100 & 5.3 & 2.1 \\
110 & 5.2 & 2.2 \\
120 & 23.1 & 2.5 \\
\hline
\end{tabular}

The influence of the ionic liquid loading (30-100 mol \% per terephthalic acid) was tested at $120^{\circ} \mathrm{C}$ with a fixed molar ratio of alcohol (1:8) (Figure 3). The optimum conditions were found below equimolar amounts of the ionic liquid ( $40-50 \mathrm{~mol} \%)$. The reaction conditions and catalyst loadings were selected to achieve the full conversion of terephthalic acid in less than $2 \mathrm{~h}$. Increasing the ionic liquid loading up to the equimolar amounts caused the decrease of the reaction rate. This can be explained as a result of the dilution of the reaction system. Ionic liquids also play the roles of water extractants, so the amount of the ionic liquid used is important to consider.

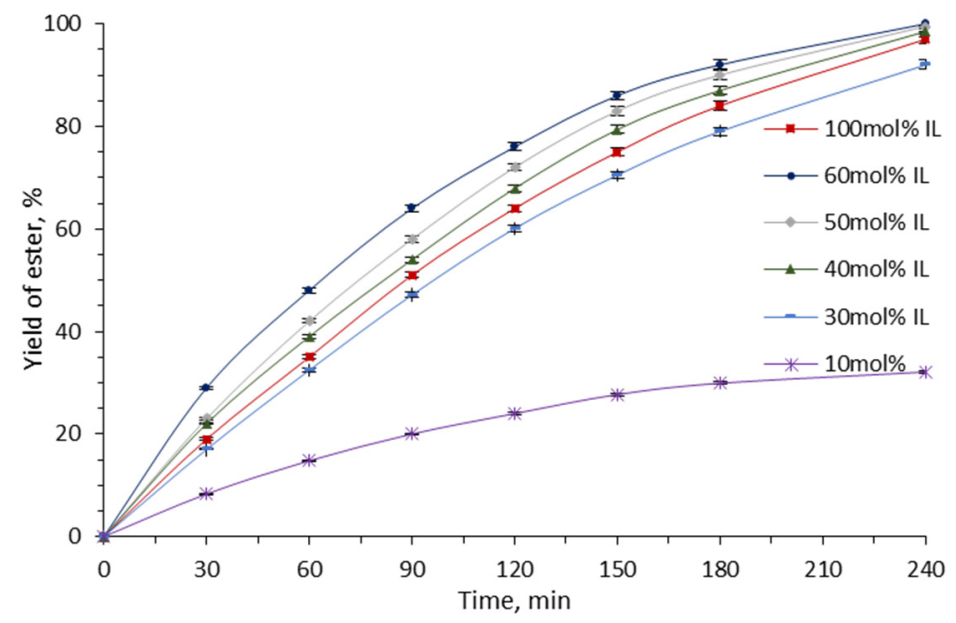

Figure 3. The influence of the ionic liquid based on $\mathrm{Et}_{3} \mathrm{~N}$ (1:2.7) loading on the yield of bis(2-ethylhexyl) terephthalate obtained in the reaction of terephthalic acid $(0.12 \mathrm{~mol})$ with 2-ethyl-1-hexanol $(0.96 \mathrm{~mol})$ at $120^{\circ} \mathrm{C}$. 
The influence of reaction temperature on the reaction time required for full acid conversion was also tested (Figure 4). Reactions were carried out in a temperature range from 90 to $120^{\circ} \mathrm{C}$. The reaction rate increased with temperature, as expected, and reached full conversion in $8 \mathrm{~h}$ at $110^{\circ} \mathrm{C}$ and only $4 \mathrm{~h}$ at $120^{\circ} \mathrm{C}$. Below $110^{\circ} \mathrm{C}$, the reaction times were much longer. Additionally, in order to check if this biphasic reaction was influenced by the mixing, the experiments were conducted at various mixing speeds (200-1000 rpm) at $120^{\circ} \mathrm{C}$. In doing so, it was observed that varying mixing speeds did not influence the reaction. All experiments were therefore carried out at $800 \mathrm{rpm}$.

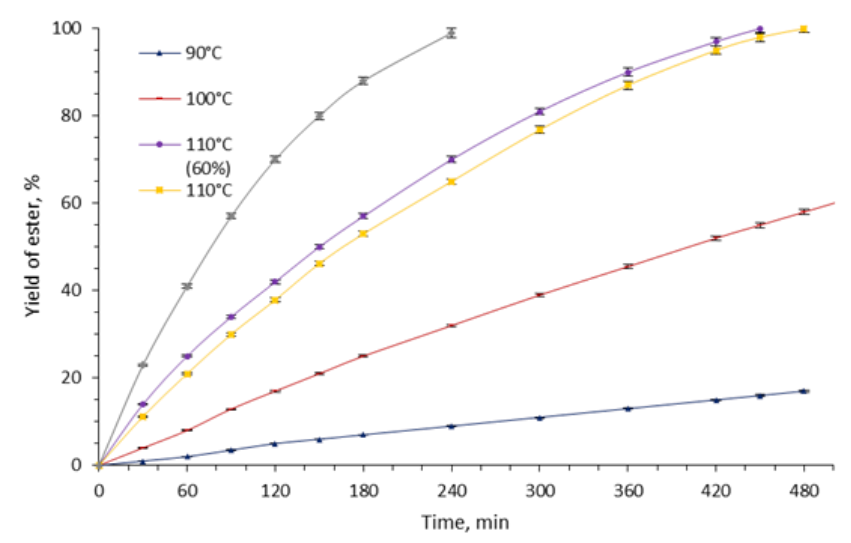

Figure 4. The influence of temperature on the yield of bis(2-ethylhexyl) terephthalate obtained in the reaction of terephthalic acid $(0.12 \mathrm{~mol})$ with 2-ethyl-1-hexanol $(0.96 \mathrm{~mol})$ in the presence of $50 \mathrm{~mol} \%$ of the ionic liquid based on $\mathrm{Et}_{3} \mathrm{~N}$ (1:2.7) (24.66 g) relative to terephthalic acid.

In the next step, the influence of the molar ratio of alcohol to terephthalic acid was determined (Figure 5). Lowering the amount of alcohol is beneficial from an economical and sustainability standpoint (smaller plant size and less energy to recover and recycle). As presented in the Figure 5, the optimum amounts of alcohol was 8:1. It was possible to carry out the reaction with a molar ratio of 6:1, but the full conversion of acid was reached after $3 \mathrm{~h}$ and $40 \mathrm{~min}$, which was a longer reaction time.

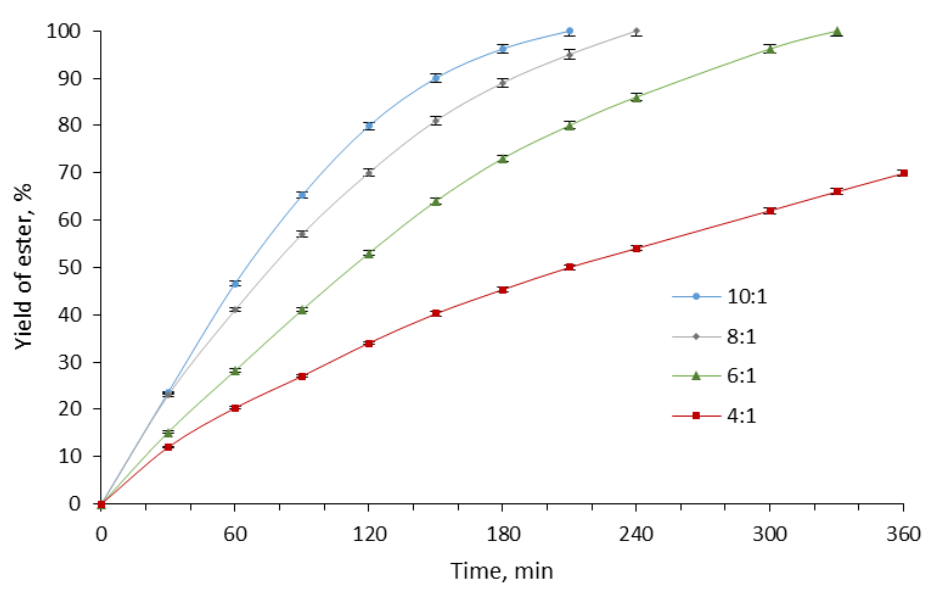

Figure 5. The influence of an excess of 2-ethyl-1-hexanol on the yield of bis(2-ethylhexyl) terephthalate obtained in the presence of $50 \mathrm{~mol} \%$ of the ionic liquid based on $\mathrm{Et}_{3} \mathrm{~N}$ (1:2.7) (24.66 g) relative to terephthalic acid at $120^{\circ} \mathrm{C}$.

The isolation of the product after the reaction was based on the simple separation of the biphasic system (Scheme 3). The upper phase was first washed with water to remove traces of the ionic liquid, and then the mixture was dried and concentrated on a rotary evaporator. Next the ester, ether, and unreacted alcohol were isolated via distillation. The water was evaporated from the bottom layer, 
and the ionic liquid was reused five times without becoming lost in activity (Figure 6). The recovery percentage of the ionic liquid after each cycle was approximately $97 \%$.

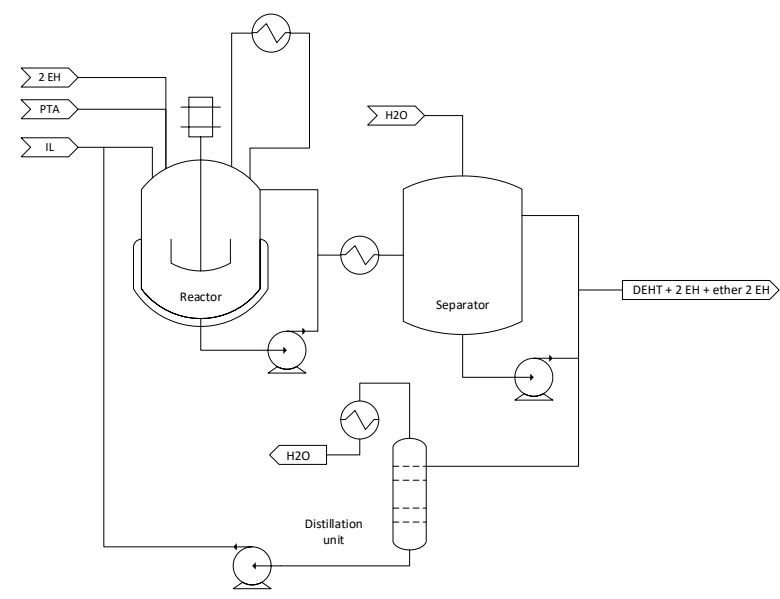

Scheme 3. The proposed block scheme for the production of bis(2-ethylhexyl) terephthalate.

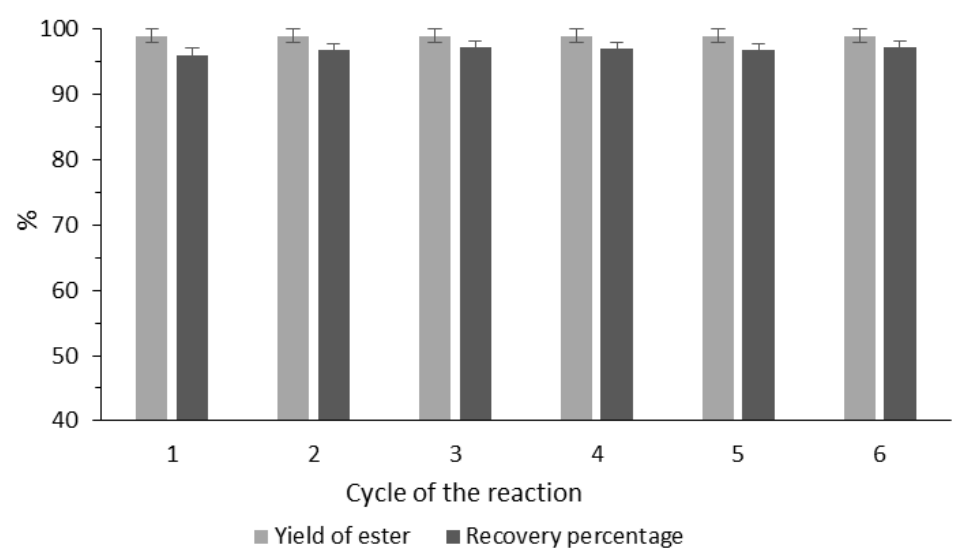

Figure 6. Recycling of ionic liquid study.

The presented esterification method was very useful for the production of bis(2-ethylhexyl) terephthalate. However, the modification of the alcohol structure to 1-butanol disrupted the reaction system. The created ester dibutyl terephthalate was partially soluble in the ionic liquid, which resulted in an only $50 \%$ conversion of terephthalic acid after $4 \mathrm{~h}$ of esterification at $120^{\circ} \mathrm{C}(50 \mathrm{~mol} \%$ of the ionic liquid relative to terephthalic acid; a 1:8 molar ratio of terephthalic acid to 1-butanol). The prolongation of reaction time caused a very slow increase in the amount of ester (up to $80 \%$ after $12 \mathrm{~h}$ ). Additionally, 1-butanol was very prone to etherification in the reaction conditions, and, as an outcome, $25 \%$ of alcohol was converted to dibutylether as a by-product. This phenomenon confirmed that the success of the proposed reaction system was based on the creation of two phases during the reaction.

It is worth noting that the synthesis of the 'forbidden' ortho-phthalate esters from phthalic anhydride would be very simple using the presented method. Phthalic anhydride is soluble in ionic liquids, and the formed bis(2-ethylhexyl) phthalate is insoluble in the ionic liquid phase (Figure 7). As a result, after the optimization of the reaction parameters using $20 \mathrm{~mol} \%$ of ionic liquid relative to phthalic anhydride and a 1:3 molar ratio of phthalic anhydride to 2-ethyl-1-hexanol at $80^{\circ} \mathrm{C}$, it was possible to obtain full conversion of anhydride to bis(2-ethylhexyl) phthalate after $90 \mathrm{~min}$. A lower temperature and a lower amount of the ionic liquid was necessary to obtain a full conversion of phthalic anhydride with the lack of ether as a by-product. 


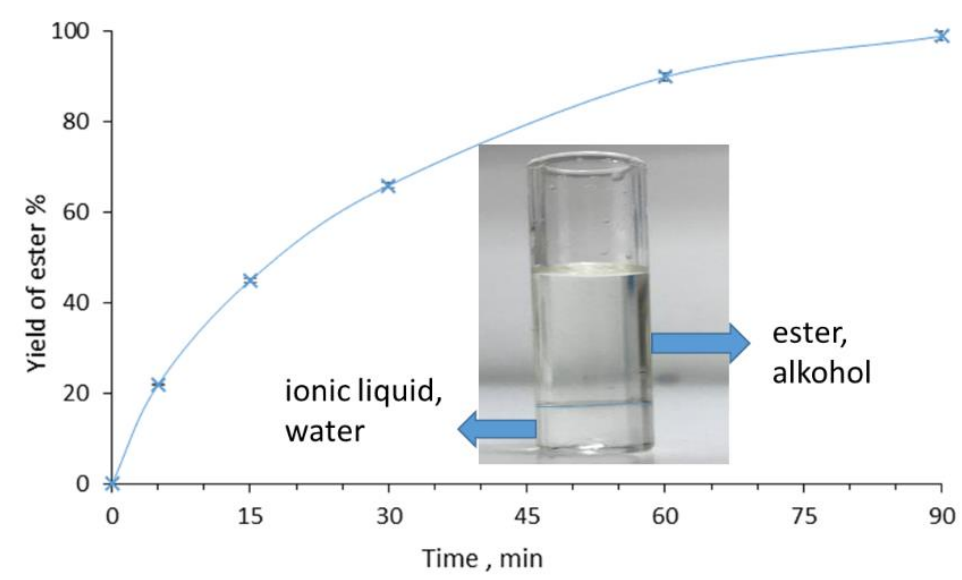

Figure 7. Yield of bis(2-ethylhexyl) phthalate obtained in the reaction of phthalic anhydride (0.12 mol) with 2-ethyl-1-hexanol $(0.96 \mathrm{~mol})$ in the presence of $20 \mathrm{~mol} \%$ of the ionic liquid based on $\mathrm{Et}_{3} \mathrm{~N}(1: 2.7)$ $(9.86 \mathrm{~g})$ relative to phthalic anhydride at $80^{\circ} \mathrm{C}$.

\section{Materials and Methods}

\subsection{Materials}

Decane, triethylamine, 1-methylimidazole, sulfuric acid (95\%), phthalic anhydride (99\%), and activated carbon were purchased from Sigma-Aldrich (Merck, Darmstadt, Germany). Terephthalic acid (99\%), n-butanol, and 1-ethyl-1-hexanol were produced at the plants of Grupa Azoty Zakłady Azotowe Kędzierzyn S.A. $\mathrm{NaHCO}_{3}$ and $\mathrm{MgSO}_{4}$ were obtained from Chempur (Krupski Mlyn, Poland) and were used without additional purification.

\subsection{Methods}

GC analyses were performed on a Shimadzu GC-2010 Plus (Kyoto, Japan) (carrier gas helium), with an oven temperature program as follows: start $80^{\circ} \mathrm{C}$ for $1 \mathrm{~min}$, next reach $300{ }^{\circ} \mathrm{C}$ with rate $40^{\circ} \mathrm{C} / \mathrm{min}$ ), and then $5 \mathrm{~min}$ at $300^{\circ} \mathrm{C}$. The Shimadzu GC-2010 Plus was equipped with a flame ionization detector (FID) and a Zebron ZB-5MSi column $(30 \mathrm{~m} \times 0.25 \mathrm{~mm} 0.25 \mu \mathrm{m}$ film). Details presented in supplementary materials.

The NMR spectra of the products were recorded using a Varian 500 spectrometer (Palo Alto, CA, USA.) at the following operating frequencies: ${ }^{1} \mathrm{H} 400 \mathrm{MHz}$ and ${ }^{13} \mathrm{C} 150 \mathrm{MHz}$. Chemical shifts are reported as parts per million (ppm) in reference to tetramethylsilane (TMS) for $0.020 \mathrm{~g}$ of the sample.

\subsection{Synthesis}

A protic ionic liquid (molar ratio of amine to $\mathrm{H}_{2} \mathrm{SO}_{4}$ 1:3, 1:2.7, 1:1.5): triethylamine (25.30 g, $0.25 \mathrm{~mol}, 1 \mathrm{~mol}$ eq.) was introduced into the batch jacket reactor $(250 \mathrm{~mL})$ with a thermometer, a condenser, and a mechanical stirrer. The water solution of sulfuric acid (38.72-77.43 g, 0.38-0.75 mol, 1.5-3 mol eq.; water $6.40-10.27 \mathrm{~g}$, and $0.36-0.57 \mathrm{~mol}$ ) was added while keeping the temperature at $40^{\circ} \mathrm{C}$ (400 rpm, $\left.20 \mathrm{~min}\right)$. Next the rector content was mixed for 1 hour at room temperature. In the end, the ionic liquid was dried $\left(80^{\circ} \mathrm{C}, 1-2 \mathrm{mbar}, 12 \mathrm{~h}\right)$. The ionic liquid was obtained with a $98 \%$ yield as a colorless liquid. ${ }^{1} \mathrm{H}$ NMR (400 MHz, DMSO) $\delta 8.95(\mathrm{~s}, 1 \mathrm{H}), 7.51$ (bs, $\left.5 \mathrm{H}\right), 3.07(\mathrm{kw}, 6 \mathrm{H}, \mathrm{J}=6.4 \mathrm{~Hz})$, $1.15(\mathrm{t}, 9 \mathrm{H}, \mathrm{J}=7.9 \mathrm{~Hz}) .{ }^{13} \mathrm{C}$ NMR $(150 \mathrm{MHz}, \mathrm{DMSO}) \delta 48.02,12.20$.

The protic ionic liquid (molar ratio of amine to $\mathrm{H}_{2} \mathrm{SO}_{4}$ 1:3): 1-methylimidazole (20.53 g, $0.25 \mathrm{~mol}$, 1 mol eq.) was introduced into the batch jacket reactor $(250 \mathrm{~mL})$ with a thermometer, a condenser, and a mechanical stirrer. The water solution of sulfuric acid $(77.43 \mathrm{~g}, 0.75 \mathrm{~mol}, 3 \mathrm{~mol}$ eq.; water $(9.80 \mathrm{~g}$, $0.54 \mathrm{~mol})$ was added while keeping the temperature at $40^{\circ} \mathrm{C}(400 \mathrm{rpm}, 20 \mathrm{~min}$. Next, the rector content was mixed for 1 hour at room temperature. In the end, the ionic liquid was dried $\left(80^{\circ} \mathrm{C}, 1-2 \mathrm{mbar}\right.$, overnight). The ionic liquid was obtained with a $99 \%$ yield as a colorless liquid. ${ }^{1} \mathrm{H}$ NMR $(400 \mathrm{MHz}$, 
DMSO) $\delta 9.01(\mathrm{~s}, 1 \mathrm{H}), 8.68(\mathrm{bs}, 6 \mathrm{H}), 7.66(\mathrm{~s}, 1 \mathrm{H}), 7.61(\mathrm{~s}, 1 \mathrm{H}), 3.84(\mathrm{~s}, 3 \mathrm{H}) .{ }^{13} \mathrm{C}$ NMR $(150 \mathrm{MHz}, \mathrm{DMSO}) \delta$ $136.23,123.60,120.14,35.82$.

Bisalkyl terephthalate: protic ionic liquid (molar ratio of amine to $\mathrm{H}_{2} \mathrm{SO}_{4} 1: 3,1: 2.7$, 1:1.5) (mol (23.47-24.66 g, $0.06 \mathrm{~mol}, 50 \mathrm{~mol} \%)$, alcohol (71.16-125.02 g, $0.96 \mathrm{~mol})$, terephthalic acid (19.94 g, $0.12 \mathrm{~mol}$, molar ratio of acid to alcohol 1:8), and decane (internal standard for GC, $3 \mathrm{~g}$ ) were introduced into the batch jacket reactor $(250 \mathrm{~mL})$ with a thermometer, a condenser, and a mechanical stirrer. Next, the reaction was mixed at $120{ }^{\circ} \mathrm{C}$ for $4-12 \mathrm{~h}$. To control the reaction progress using GC analysis, the samples were taken from the upper phase. In the end, the upper phase, after separation, was washed with water $(10 \mathrm{~mL})$ to get rid of the ionic liquid. The organic layer was concentrated. During the distillation of the organic layer, the alcohol was removed at $63-65^{\circ} \mathrm{C}(10 \mathrm{mmHg})$ for 2-ethyl-1-hexanol and $117-119^{\circ} \mathrm{C}$ for 1-butanol. After the evaporating of the alcohol, the ether was removed at $130-131^{\circ} \mathrm{C}$ (10 $\mathrm{mmHg}$ ) for bis(2-ethylhexyl) ether and $76-77^{\circ} \mathrm{C}(100 \mathrm{mmHg})$ for dibutyl ether. Finally, the product was decolorized using activated carbon. Bis(2-ethylhexyl) terephthalate was obtained with a $95 \%$ yield (46.40 g) as a colorless liquid: ${ }^{1} \mathrm{H}$ NMR $(400 \mathrm{MHz}, \mathrm{DMSO}) \delta: 8.08(\mathrm{~s}, 4 \mathrm{H}), 4.24(\mathrm{td}, \mathrm{J}=7.6,3.7 \mathrm{~Hz}, 4 \mathrm{H})$, 1.74-1.65 (m, 2H), 1.27-1.45 (m, 16H), $0.91(\mathrm{t}, \mathrm{J}=7.5 \mathrm{~Hz} 6 \mathrm{H}), 0.88(\mathrm{t}, \mathrm{J}=7.4 \mathrm{~Hz}, 6 \mathrm{H}) .{ }^{13} \mathrm{C}$ NMR $(150 \mathrm{MHz}$, DMSO) $\delta: 165.01,133.74,129.44,67.12,38.25,29.91,28.37,23.40,22.37,13.87,10.88$.

Dibutyl terephthalate was obtained as a colorless liquid with a $75 \%$ yield $(26.72 \mathrm{~g}) .{ }^{1} \mathrm{H}$ NMR $\left(400 \mathrm{MHz}, \mathrm{CDCl}_{3}\right) \delta 8.07(\mathrm{~s}, 4 \mathrm{H}), 4.30(\mathrm{t}, \mathrm{J}=6.5 \mathrm{~Hz}, 4 \mathrm{H}), 1.70$ (quin, $\left.\mathrm{J}=7.5 \mathrm{~Hz}, 4 \mathrm{H}\right), 1.42(\mathrm{sext}, \mathrm{J}=7.4 \mathrm{~Hz}$, $4 \mathrm{H}), 0.93(\mathrm{t}, \mathrm{J}=7.3 \mathrm{~Hz}, 6 \mathrm{H}) .{ }^{13} \mathrm{C}$ NMR (150 MHz, DMSO) $\delta: ~ 165.03,133.73,129.43,64.86,30.16$, $18.71,13.57$.

Bis(2-ethylhexyl) phthalate: protic ionic liquid (molar ratio of amine to $\mathrm{H}_{2} \mathrm{SO}_{4}$ 1:2.7) (9.86 g, $0.02 \mathrm{~mol}, 20 \mathrm{~mol} \%)$, 2-ethyl-1-hexanol (125.02 g, $0.96 \mathrm{~mol})$, phthalic anhydride (17.77 g, $0.12 \mathrm{~mol}$, molar ratio of acid to 2-ethyl-1-hexanol 1:8), and decane (internal standard for GC, $3 \mathrm{~g}$ ) were introduced into the batch jacket reactor $(250 \mathrm{~mL})$ with a thermometer, a condenser, and a mechanical stirrer. The reaction mixture was stirred at $80^{\circ} \mathrm{C}$ for $90 \mathrm{~min}$. To control the reaction progress using GC analysis, the samples were taken from the upper phase. In the end, the upper phase, after separation, was washed with water $(10 \mathrm{~mL})$ to get rid of the ionic liquid. The organic layer was concentrated. During the distillation of the organic layer, the alcohol was removed at $63-65^{\circ} \mathrm{C}(10 \mathrm{mmHg})$. Bis(2-ethylhexyl) phthalate was obtained with a $96 \%$ yield $\left(46.40 \mathrm{~g}\right.$ ) of as a colorless liquid. ${ }^{1} \mathrm{H}$ NMR $(400 \mathrm{MHz}$, DMSO) $\delta$ $7.73-7.65(\mathrm{~m}, 4 \mathrm{H}), 4.13(\mathrm{td}, \mathrm{J}=5.7,3.5 \mathrm{~Hz}, 4 \mathrm{H}), 1.68-1.58(\mathrm{~m}, 2 \mathrm{H}), 1.24-1.43(\mathrm{~m}, 16 \mathrm{H}), 0.88(\mathrm{t}, \mathrm{J}=6.7 \mathrm{~Hz}$, $6 \mathrm{H}), 0.85(\mathrm{t}, \mathrm{J}=6.7 \mathrm{~Hz}, 6 \mathrm{H})$.

\subsection{Recycling Studies}

In order to recycle the catalyst, after the reaction was carried out in the presence of $50 \mathrm{~mol} \%$ of the ionic liquid, the upper phase was decanted, and the lower, ionic liquid phase was washed with water and dried $\left(80^{\circ} \mathrm{C}, 1-2 \mathrm{mbar}, 12 \mathrm{~h}\right)$.

\section{Conclusions}

In conclusion, in this work, an efficient method for the synthesis of an alternative bis(2-ethylhexyl) terephthalate plasticizer was presented. The activity of the proposed protic ionic liquids in $120{ }^{\circ} \mathrm{C}$ was far above conventional organometallic compounds working at $160-270^{\circ} \mathrm{C}$, which, in turn, led to a both greener and mote economically viable process. Protic ionic liquids can compete with the cheapest pretreatment chemicals, such as sulfuric acid and triethylamine, in terms of effectiveness and process cost, removing ionic liquid cost as a barrier to the economic viability of ionic liquids-based esterification. In order to translate these findings to an industrially viable proposition, scaled-up experiments are necessary. This stage of research is currently under investigation in our group.

Supplementary Materials: The following are available online at http://www.mdpi.com/2073-4344/10/4/457/s1, NMR analysis of esters and conditions of GC analysis of reaction mixtures.

Author Contributions: Conceptualization, A.C.; data curation, A.G., P.L., K.M., K.E. and N.B.; formal analysis, E.P. and A.C.; funding acquisition, E.P. and A.C.; investigation, A.G. and P.L; methodology, A.G., P.L., K.M. and 
K.E; software, P.L.; supervision, E.P.; visualization, A.G.; writing-original draft, A.C.; writing-review and editing, A.G., P.L. and K.M. All authors have read and agreed to the published version of the manuscript.

Funding: This research was funded by the company Grupa Azoty Zakłady Azotowe Kędzierzyn S.A. P.L. also acknowledges the National Agency for Academic Exchange of Poland (under the Academic International Partnerships program, grant agreement PPI/APM/2018/1/00004).

Conflicts of Interest: The authors declare no conflict of interest.

\section{References}

1. Jamarani, R.; Erythropel, H.C.; Nicell, J.A.; Leask, R.L.; Maric, M. How green is your plasticizer? Polymers 2018, 10, 834. [CrossRef] [PubMed]

2. Jia, P.; Xia, H.; Tang, K.; Zhou, Y. Plasticizers derived from biomass resources: A short review. Polymers 2018, 10, 1303. [CrossRef] [PubMed]

3. Kumar, S. Recent developments of biobased plasticizers and their effect on mechanical and thermal properties of Poly(vinyl chloride): A review. Ind. Eng. Chem. Res. 2019, 58, 11659-11672. [CrossRef]

4. Ball, G.L.; McLellan, C.J.; Bhat, V.S. Toxicological review and oral risk assessment of terephthalic acid (TPA) and its esters: A category approach. Crit Rev. Toxicol. 2012, 42, 28-67. [CrossRef] [PubMed]

5. Nakajima, I.; Takai, M. Method for Producing Terephthalic Acid Diester. JP 2004300078, 28 October 2004. Available online: https://patents.google.com/patent/JP2004300078A/en (accessed on 1 April 2020).

6. Nakajima, I.; Takai, M. Method for Producing Terephthalic Acid Diester. JP 2004339075, 2 December 2004. Available online: https://patents.google.com/patent/JP2004339075A/en?oq=JP+2004339075 (accessed on 1 April 2020).

7. Matsumoto, S. Catalyst for Esterification and Transesterification and Process for Producing Ester. U.S. Patent 2005/0176986, 18 April 2005.

8. Ikeda, H.; Inoue, T.; Takahashi, K. Method for Producing Diester of Terephthalic Acid. JP 2005306759, 4 November 2005. Available online: https://patents.google.com/patent/JP2005306759A/en?oq=JP+2005306759 (accessed on 1 April 2020).

9. Matsuo, T.; Nakajima, I.; Takai, M. Method for Producing Terephthalic Acid Diester. JP 2006273799, 12 October 2006. Available online: https://patents.google.com/patent/JP2006273799A/en?oq=JP+2006273799 (accessed on 1 April 2020).

10. Osborne, V.H.; Turner, P.W.; Cook, S.L. Production of Terephthalic Acid Di-Esters. WO 2008/094396, 7 August 2008. Available online: https://patents.google.com/patent/WO2008094396A1/en?oq=WO+2008\%2f094396 (accessed on 1 April 2020).

11. Nakajima, I.; Takai, M. Method for Producing Terephthalic Acid Diester. JP 2009185040, 20 August 2009. Available online: https://patents.google.com/patent/JP2009185040A/en?oq=JP+2009185040 (accessed on 1 April 2020).

12. Sutor, E.; Grzybek, R.; Grymel, A.; Janik, L.; Trybuła, J.; Tkacz, B.; Fiszer, R.; Krueger, A.; Jasienkiewicz, J.; Filipiak, B.; et al. Process for the Preparation of Dioctyl Terephthalate. PL 216179, 31 March 2014. Available online: https://patents.google.com/patent/PL216179B1/en?oq=PL+216179 (accessed on 1 April 2020).

13. Grass, M. Dialkyl Terephthalates and Their Use. U.S. Patent 20070179229, 2 August 2007.

14. Matuszek, K.; Pankalla, E.; Grymel, A.; Latos, P.; Chrobok, A. Studies on the Solubility of Terephthalic Acid in Ionic Liquids. Molecules 2020, 25, 80. [CrossRef] [PubMed]

15. Kaller, A.S.M.; Bronneberg, R.; Stammer, J.; Das, M.; Harnischmacher, G. Method for Producing Diesters of Terephthalic Acid with A Dehydration of Recirculated Alcohol. WO 2016046118A1, 31 March 2016. Available online: https:/patents.google.com/patent/WO2016046118A1/en?oq=WO+2016046118A1 (accessed on 1 April 2020).

16. Lin, J.Q.; Fang, G.; Jin, C.; Sun, Y.; Zuo, S.; Qian, C.; Lin, W.; Zang, X.; Liu, L.; Chen, Y. Method for Synthesizing Dioctyl Terephthalate Through Esterification. CN 102001948A, 6 April 2011. Available online: https://patents.google.com/patent/CN102001948A/en?oq=CN102001948A (accessed on 1 April 2020).

17. Xuesong, P. Production Method of Dioctyl Terephthalate. CN 102701984A, 3 October 2012. Available online: https://patents.google.com/patent/CN102701984A/en?oq=CN102701984A (accessed on 1 April 2020). 
18. Hongyun, G.; Maolin, T.; Lingling, L.; Chenxi, L.; Maohua, D. Applications of Acidic Functionalized Ion Liquid in Esterification Reaction. CN 103752340A, 30 April 2014. Available online: https://patents.google. com/patent/CN103752340A/en?oq=CN103752340A (accessed on 1 April 2020).

19. Matuszek, K.; Chrobok, A.; Coleman, F.; Seddon, K.R.; Swadźba-Kwaśny, M. Tailoring ionic liquid catalysts: Structure, acidity and catalytic activity of protonic ionic liquids based on anionic clusters, $\left[\left(\mathrm{H}_{\mathrm{S}} \mathrm{O}_{4}\right)\left(\mathrm{H}_{2} \mathrm{SO}_{4}\right) \mathrm{x}\right]^{-}$ $(\mathrm{x}=0,1$, or 2). Green Chem. 2014, 16, 3463-3471. [CrossRef]

20. Dorosz, U.; Barteczko, N.; Latos, P.; Erfurt, K.; Pankalla, E.; Chrobok, A. Highly efficient biphasic system for the synthesis of alkyl lactates in the presence of acidic ionic liquids. Catalysts 2020, 10, 37. [CrossRef]

21. Chiappe, C.; Rajamani, S.; D'Andrea, F. A dramatic effect of the ionic liquid structure in esterification reactions in protic ionic media. Green Chem. 2013, 15, 137-143. [CrossRef]

22. George, A.; Brandt, A.; Tran, K.; Zahari, S.M.S.N.S.; Klein-Marcuschamer, D.; Sun, N.; Sathitsuksanoh, N.; Shi, J.; Stavila, V.; Parthasarathi, R.; et al. Design of low-cost ionic liquids for lignocellulosic biomass pretreatment. Green Chem. 2015, 17, 1728-1734. [CrossRef]

23. Gutmann, V. The Donor-Acceptor Approach to Molecular Interactions; Plenum Press: New York, NY, USA, 1978.

(C) 2020 by the authors. Licensee MDPI, Basel, Switzerland. This article is an open access article distributed under the terms and conditions of the Creative Commons Attribution (CC BY) license (http://creativecommons.org/licenses/by/4.0/). 